\title{
Functional correlates of Apolipoprotein E genotype in Frontotemporal Lobar Degeneration
}

\author{
Barbara Borroni*1, Daniela Perani ${ }^{2}$, Silvana Archetti ${ }^{3}$, Chiara Agosti ${ }^{1}$, \\ Barbara Paghera ${ }^{4}$, Giuseppe Bellelli ${ }^{5}$, Monica Di Luca ${ }^{6}$ and \\ Alessandro Padovani ${ }^{1}$
}

Address: ${ }^{1}$ Centre for Aging Brain and Neurodegenerative Disorders, Department of Neurology, University of Brescia, Italy, ${ }^{2}$ Vita-Salute H San Raffaele University, IRCCS H San Raffaele, Institute of Bioimaging and Molecular Physiology, Milan, Italy, ${ }^{3}$ Department of Laboratories and Diagnostics, University of Brescia, Brescia, Italy, ${ }^{4}$ Nuclear Medicine, Brescia Hospital, Brescia, Italy, ${ }^{5}$ Geriatric Unit, "Ancelle della Carità" Hospital, Cremona, Italy and ${ }^{6}$ Centre of Excellence for Neurodegenerative Disorders and Department of Pharmacology, University of Milan, Italy

Email: Barbara Borroni* - bborroni@inwind.it; Daniela Perani - perani@unimi.it; Silvana Archetti - sarchetti@tiscali.it; Chiara Agosti - chiara.agosti@fastweb.it; Barbara Paghera - bpaghera@inwind.it; Giuseppe Bellelli - gbellelli@libero.it; Monica Di Luca-diluca@unimi.it; Alessandro Padovani - padovani@med.unibs.it

* Corresponding author

Published: 24 August 2006

BMC Neurology 2006, 6:31 doi:10.1|186/|47|-2377-6-31
Received: 28 April 2006

Accepted: 24 August 2006

This article is available from: http://www.biomedcentral.com/I47/-2377/6/3।

(C) 2006 Borroni et al; licensee BioMed Central Ltd.

This is an Open Access article distributed under the terms of the Creative Commons Attribution License (http://creativecommons.org/licenses/by/2.0), which permits unrestricted use, distribution, and reproduction in any medium, provided the original work is properly cited.

\begin{abstract}
Background: It has been recently demonstrated that in Frontotemporal Lobar Degeneration (FTLD) memory deficits at presentation are commoner than previously thought. Apolipoprotein $E$ (ApoE) genotype, the major genetic risk factor in sporadic late-onset Alzheimer Disease (AD), modulates cerebral perfusion in late middle-age cognitively normal subjects. ApoE $\varepsilon 4$ homozygous have reduced glucose metabolism in the same regions involved in AD.

The aim of this study was to determine whether ApoE genotype might play a key-role in influencing the cerebral functional pattern as well as the degree of memory deficits in FTLD patients.

Methods: Fifty-two unrelated FTLD patients entered the study and underwent a somatic and neurological evaluation, laboratory examinations, a brain structural imaging study, and a brain functional Single Photon Emission Tomography study. ApoE genotype was determined.

Results: ApoE genotype influenced both clinical and functional features in FTLD. ApoE $\varepsilon 4$-carriers were more impaired in long-term memory function (ApoE $\varepsilon 4 \mathrm{vs.} \mathrm{ApoE} \mathrm{non} \varepsilon 4,6.3 \pm 3.9$ vs. 10.1 $\pm 4.2, p=0.004)$ and more hypoperfused in uncus and parahippocampal regions $(x, y, z=38,-6,-20$, $\mathrm{T}=2.82$, cluster size $=100$ voxels; $-32,-12,-28, T=2.77$, cluster size $=40$ voxels $)$.

Conclusion: The present findings support the view that ApoE genotype might be considered a disease-modifying factor in FTLD, thus contributing to define a specific clinical presentation, and might be of relevance for pharmacological approaches.
\end{abstract}

\section{Background}

Frontotemporal Lobar Degeneration (FTLD) is a complex neurodegenerative syndrome whose broad phenotype is characterised by personality changes, behavioural disturbances, impairment in language, and in executive functions [1]. 
Memory deficits are not considered prominent characteristics at disease onset, but more recent studies demonstrated that amnesia at presentation in pathologically proved FTLD cases is commoner than previously thought [2]. Notwithstanding, the underlying basis of such impairment is still unexplained.

Apolipoprotein E (ApoE) is established as the major genetic risk factor in sporadic late-onset Alzheimer Disease $(A D)$, which is mainly characterised by memory impairment [3]. Moreover, it has been demonstrated that ApoE genotype modulates cerebral perfusion in late middle-age cognitively normal subjects, ApoE $\varepsilon 4$ homozygous having reduced glucose metabolism in the same regions involved in $\mathrm{AD}[4]$.

Based on these observations, we hypothesised that ApoE genotype might play a key-role in influencing the cerebral functional pattern as well as the degree of memory deficits in FTLD patients. To this aim, FTLD patients were enrolled, ApoE genotype defined, and neuropsychological standardized assessment as well as Single Photon Emission Tomography (SPECT) cerebral perfusion patterns assessed.

\section{Methods \\ Subjects}

This is a cross-sectional study of patients consecutively recruited from a large sample assessed at the Centre for Aging Brain and Neurodegenerative Diseases, University of Brescia, Italy.

All patients fulfilled international consensus criteria for FTLD [5-7]. In keeping with other studies, we retain the term FTLD as a general super-ordinate label with a subsequent subdivision into five major clinical subtypes : 1 . Behavioural or frontal variant FTD (fvFTD) [7], 2. Semantic Dementia (SD) [7], 3. Progressive Non-fluent Aphasia (PNFA) [7], 4. Progressive Supranuclear Palsy (PSP) [6], and 5. Corticobasal Degeneration (CBD) [5].

All subjects performed a somatic and neurological evaluation, laboratory examinations, a brain structural Magnetic Resonance Imaging study, and a brain functional SPECT study. ApoE genotype was determined. Thirty-two out of 52 patients (60\%) performed cerebrospinal fluid (CSF) Tau, Phospho-Tau and Abeta dosage to further confirm FTLD diagnosis, being Abeta dosage within the normal range and thus further excluding other kind of dementia, i.e. AD.

The diagnostic assessment included a review of full medical history, a semistructured neurological examination, including motor subscale of Unified Parkinson Disease Rating Scale, and a complete mental status evaluation by two independent and experienced neurologists; only patients with full consensus agreement by both neurologists were enrolled.

Global cognitive function assessment was made according to a standardized battery, including the Mini-Mental State Examination (MMSE) [8]. The neuropsychological assessment was made with the following tests: Raven Colored Progressive Matrices [9], Controlled Oral Word Association Test and Category Fluency [10], Clock Drawing Test [11], Rey Complex Figure Copy and Recall [12], Story Recall Test [13], Digit Span [14], Trail Making Test A and B [15], Token Test [16], and De Renzi Imitation Test [17]. Instrumental Activities of Daily Living (IADL) [18], and Basic Activities of Daily Living (BADL) [19] were assessed as well. Behavioural and psychiatric disturbances were evaluated by Neuropsychiatry Inventory (NPI) [20], and Frontal Behavioral Inventory (FBI) [21].

Stringent exclusion/inclusion criteria were applied, as follows: a) cerebrovascular disorders, previous stroke, hydrocephalus, and intra-cranial mass, documented by MRI; b) a history of traumatic brain injury or another neurologic disease; c) another extrapyramidal syndrome (e.g. Parkinson disease, Lewy Body Disease, Vascular Parkinsonism, Multiple System Atrophy), according to current clinical criteria; d) significant medical problems; e) major depressive disorder, bipolar disorder, schizophrenia, substance use disorder, or mental retardation.

Inclusion criteria: a) mild cognitive decline (Mini-Mental State Examination, MMSE $\geq 18$ ), to avoid confounds in functional data analysis; b) evidence of frontotemporal hypoperfusion in single subject analysis, excluding subjects with temporo-parietal involvement mimicking AD pattern; c) CSF Abeta levels $>800 \mathrm{pg} / \mathrm{ml}$, when available.

For brain functional data comparisons, a group of healthy subjects $(\mathrm{n}=15$, mean age $\pm \mathrm{SD}=56.3 \pm 15.4)$ were recruited, and underwent a brain SPECT study.

All participants were made fully aware about the aims of the research and the signature of an informed consent was sought from all subjects. The work was conducted in accordance with local clinical research regulations and conformed to the Helsinki Declaration.

\section{ApoE genotype analysis}

Genomic DNA was extracted from blood samples according to standard procedures. Genetic variation at the ApoE locus was determined by restriction isotyping using FTLDR amplification and subsequent digestion with Hha I (New England Biolabs). Clinical diagnosis and SPECT analysis were performed in blind to ApoE genotype. 


\section{9m Tc-ECD SPECT acquisition and processing}

Subjects were administered an intravenous injection of $1110 \mathrm{MBq}$ 99mTc-ECD (ethylcysteinate dimer, Neurolite, Bristol-Myers Squibb Pharma), and were imaged a dualhead rotating gamma camera (VG MILLENIUM GE), according with European procedure guidelines [22].

Basic image processing and voxel-based data analyses were performed by SPM02 routines (Wellcome Department of Cognitive Neurology, London, UK) implemented in MATLAB 6.1 (Mathworks, Sherborn, MA) [23]. SPECT images were spatially normalized by affine 12-parameter transformation onto a SPECT template conforms to the Talairach and Tournoux space. Normalized images were represented on a $79 \times 95 \times 68$ matrix with $2 \times 2 \times 2 \mathrm{~mm}$ voxel size. To account for individual variability in structure-function relationships, an isotropic Gaussian filter was used to smooth the spatially normalized SPECT images with a FWHM of $8 \mathrm{~mm}$.

\section{Statistical analysis}

Differences between demographic and clinical characteristics according to ApoE genotype were evaluated by Mann-Whitney test and Chi-Square test, as indicated. Results are expressed as percentage or mean \pm Standard Deviation. The significant level was set at $p<0.05$.

In regard to SPECT data, global differences in the distribution of the tracer's uptake and age effect on it were covariated out for all voxels [9]. Comparisons across the different groups were made using $t$-statistics with appropriate linear contrasts. Threshold was set at $p<0.01$ (minimum cluster size $=40$ voxels .

\section{Results \\ Subject characteristics}

Fifty-five patients with the clinical diagnosis of FTLD entered the study from March 2003 through April 2005. Among them, three were subsequently excluded to avoid confounds: one because of SPECT perfusion pattern involving temporo-parietal region and cingulate areas, and two because of low CSF Abeta and high CSF Tau levels, thus resembling AD pattern.

Fifty-two unrelated FTLD patients were finally included (23 fvFTD, 3 SD, 2 PNFA, 14 PSP, 10 CBD). Overall, FTLD patients showed mild impairment $(\mathrm{MMSE}=25.0 \pm 4.1)$. fvFTD showed behavioural disturbances, SD and PNFA were characterized by language deficits, whilst PSP and CBD had visuo-spatial impairment.

\section{ApoE genotype and patients' characteristics}

Seventeen FTLD patients (32.7\%) carried at least one ApoE $\varepsilon 4$ allele (9/23 fvFTD, 2/3 SD, 1/2 PNFA, 3/14 PSP, and 2/10 CBD).
The whole FTLD patient group was divided into two subgroups, according to the presence (ApoE $\varepsilon 4+$ ) or the absence (ApoE $\varepsilon 4$-) of ApoE $\varepsilon 4$ allele. Demographic and clinical characteristics of ApoE $\varepsilon 4$ - and ApoE $\varepsilon 4+$ patients are reported in Table 1 . The two subgroups neither differed for global cognitive impairment or for IADL or BADL scores. ApoE $\varepsilon 4+$ carriers showed worse performances in Short Story recall compared to ApoE ع4- (6.3 \pm 3.9 vs. $10.1 \pm 4.2, \mathrm{p}=0.004)$. Raven Colored Progressive Matrice scores were worse in ApoE $\varepsilon 4+$ carriers, but the performance was within the normal range in both subgroups (ApoE $\varepsilon 4+$ vs. ApoE $\varepsilon 4-, 19.0 \pm 7.0$ vs. $24.6 \pm 5.5$, $\mathrm{p}=0.003)$.

\section{Perfusion pattern according to ApoE genotype}

The cerebral perfusion assessment in the whole FTLD group as well as in ApoE \&4- and in ApoE ع4+ FTLD subgroups revealed a significant frontotemporal involvement compared to controls (data not shown).

The direct comparison of the perfusion pattern between ApoE $\varepsilon 4+v s$. ApoE $\varepsilon 4$ - demonstrated a significant bilateral hypoperfusion in uncus and in parahippocampal gyrus $(\mathrm{x}, \mathrm{y}, \mathrm{z}=38,-6,-20, \mathrm{~T}=2.82 ;-32,-12,-28, \mathrm{~T}=2.77$, see Fig. 1 and Table 2$)$ and in medial frontal cortex $(-12,12,-12, \mathrm{~T}$ $=3.48$ ) in the former group. Notably, in ApoE $\varepsilon 4+$ carriers the typical $\mathrm{AD}$ pattern, involving posterior parietal regions, was not found.

When the opposite comparison was considered, and the greater hypoperfusion in ApoE \&4- vs. ApoE $\varepsilon 4+$ was evaluated, no voxels above the threshold were found.

In order to exclude the effect of clinical endophenotypes in determining the hypoperfusion pattern, the clinical diagnoses (fvFTD, SD, PNFA, PSP and CBD) were introduced as nuisance variable in the analysis, and the results were confirmed. Thus, we concluded that the SPECT hypoperfusion pattern was not due to a specific clinical endophenotype, but only to ApoE genotype.

\section{Discussion}

The present study demonstrates that in a large series of mildly affected FTLD patients, ApoE $\varepsilon 4+$ allele can influence the phenotypic expression, accounting for a greater susceptibility to uncus and parahippocampal functional impairment. Indeed, this functional pattern is associated with worse performances in test tapping long term memory functions.

It has been recently highlighted that FTLD may be characterised by memory impairment, but the possible genetic determinants of the so called amnestic FTLD have not been identified yet [2]. The autopsy-proven evidence of amnesic deficits in FTLD has suggested that pathologies 
Table I: Demographic and clinical characteristics according to Apolipoprotein E genotype.

\begin{tabular}{|c|c|c|c|c|}
\hline Variable & ApoE $\varepsilon 4-(n=35)$ & ApoE $\varepsilon 4+(n=17)$ & Normal data ${ }^{\wedge}$ & $\mathbf{p}^{\ddagger}$ \\
\hline Age, years & $67.1 \pm 9.3$ & $68.0 \pm 6.9$ & - & .73 \\
\hline Gender, female\% & $51.4 \%$ & $64.7 \%$ & - & $.37 \dagger$ \\
\hline Education, years & $7.7 \pm 4.2$ & $6.9 \pm 2.7$ & - & .99 \\
\hline Family History, \% & 17.1 & 17.6 & - & .88 \\
\hline Age at onset, years & $64.6 \pm 8.8$ & $65.0 \pm 6.9$ & - & .96 \\
\hline Estimated disease duration, years & $2.6 \pm 2.2$ & $2.3 \pm 1.2$ & - & .94 \\
\hline MMSE & $25.3 \pm 3.9$ & $24.4 \pm 4.5$ & 24 & .54 \\
\hline UPDRS-III & $14.7 \pm 11.4$ & $10.6 \pm 10.9$ & 0 & .15 \\
\hline IADL, lost functions & $1.2 \pm 1.9$ & $2.2 \pm 2.2$ & 0 & .16 \\
\hline BADL, lost functions & $0.6 \pm 1.1$ & $0.7 \pm 1.1$ & 0 & .33 \\
\hline Short Story & $10.1 \pm 4.2$ & $6.3 \pm 3.9$ & 7.5 & .004 \\
\hline Rey Figure, copy & $27.3 \pm 6.7$ & $23.7 \pm 9.2$ & 29 & .15 \\
\hline Rey Figure, recall & $12.5 \pm 5.5$ & $10.9 \pm 7.5$ & 15 & .21 \\
\hline Raven Coloured Matrices & $24.6 \pm 5.5$ & $19.0 \pm 7.0$ & 17.5 & .003 \\
\hline Verbal Fluency & $25.1 \pm 10.7$ & $20.6 \pm 10.4$ & 16 & .13 \\
\hline Set Test & $31.0 \pm 9.3$ & $26.6 \pm 9.6$ & 24 & .13 \\
\hline Digit Span & $5.6 \pm 1.4$ & $5.4 \pm 1.7$ & 3.75 & .70 \\
\hline Token Test & $30.2 \pm 4.3$ & $27.1 \pm 5.4$ & 29 & .06 \\
\hline Trail Making A, ES $=0$ or 1 & $41.0 \%$ & $66.0 \%$ & $>1$ & $.48^{\dagger}$ \\
\hline Trail Making B, ES $=0$ or $\mathrm{I}$ & $50.0 \%$ & $73.0 \%$ & $>1$ & $.44 \dagger$ \\
\hline De Renzi Imitation Test & $64.3 \pm 12.2$ & $66.1 \pm 9.0$ & 62 & .94 \\
\hline
\end{tabular}

ApoE: Apolipoprotein E; MMSE: Mini-Mental State Examination; UPDRS: Unified Parkinson Disease Rating Scale; IADL: Instrumental Activities of Daily Living; BADL: Basic Activities of Daily Living; ES: Equivalent Score. Neuropsychological test scores were corrected for age and education; ^ defined according to available Italian normative data. $\ddagger$ Mann-Whitney test; $\dagger$ Chi-Sqare test. Results are expressed as percentage or mean \pm Standard Deviation. The significant level was set at $p<0.05$.

mainly characterised by memory impairment, such as AD, could share the same genetic risk factors.

In $\mathrm{AD}$, the role of ApoE genotype is well established [24], and it has been recently demonstrated that ApoE genotype modifies the phenotype in AD patients, the lack of ApoE $\varepsilon 4$ directing away the pathological process from medial temporal structures [4].
ApoE genotype affects not only AD, but it may also cognitive performances in normal aging, $\varepsilon 4$ allele-carriers showing altered memory-related cognitive processing [25]. Furthermore, cross-sectional positron emission tomography studies found that cognitively normal carriers of the ApoE $\varepsilon 4$ allele have abnormally low measurements of the cerebral metabolic rate for glucose in the same regions as patients with $\mathrm{AD}$.

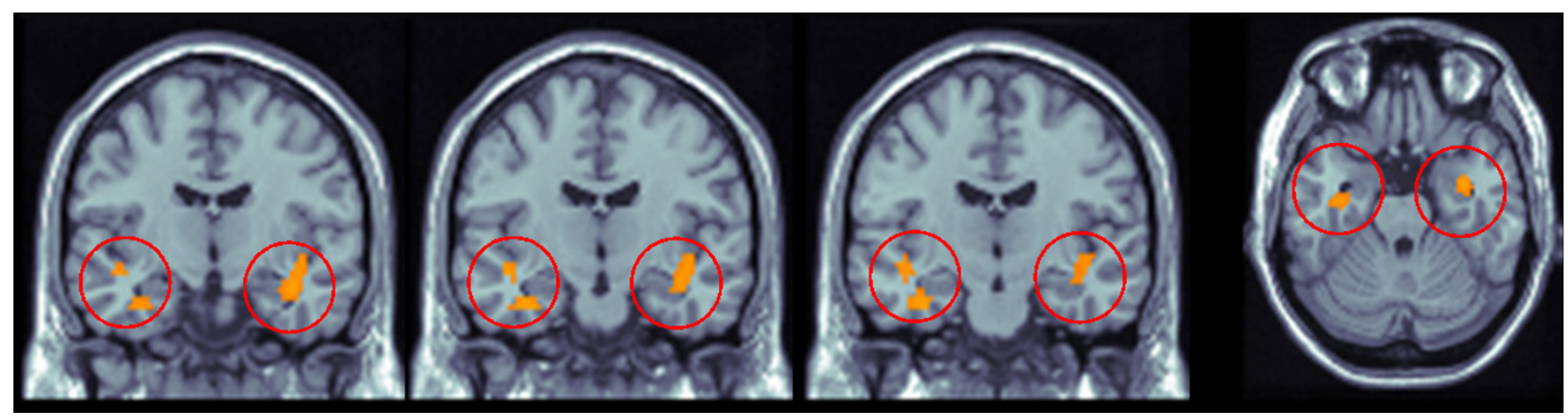

Figure I

Hypoperfusion pattern in Frontotemporal Lobar Degeneration ApoE ع4+ compared to ApoE ع4- carriers: bilateral hippocampal structure involvement. The direct comparison of the perfusion pattern between Apolipoprotein (ApoE) $\varepsilon 4+$ vs. ApoE $\varepsilon 4-$ demonstrated a significant bilateral hypoperfusion in uncus and in parahippocampal gyrus. Talairach and Tournoux coordinates. Coronal slices $y=-8$ to $-I 3$, axial slice $z=-24, p<0.0 I, T>2.4 I$, minimum cluster size $=40$ voxels. Functional patterns superimposed to standard TI weighted MRI. 
Table 2: Location of the peaks of more hypoperfused areas in patients with Frontotemporal Lobar Degeneration carrying Apolipoprotein E $\varepsilon 4$ allele.

\begin{tabular}{|c|c|c|c|c|c|}
\hline \multirow[t]{2}{*}{ Area } & \multicolumn{3}{|c|}{ Peak coordinates $(\mathrm{mm})$} & \multirow[t]{2}{*}{$\mathbf{T}$} & \multirow[t]{2}{*}{ Cluster size } \\
\hline & $\mathbf{x}$ & $\mathbf{y}$ & $\mathbf{z}$ & & \\
\hline \multicolumn{6}{|l|}{ ApoE $\varepsilon 4+$ vs. ApoE $\varepsilon 4-*$} \\
\hline \multirow[t]{2}{*}{ Uncus and parahippocampal gyrus $(R, L)$} & 38 & -6 & -20 & 2.82 & 100 \\
\hline & -32 & -12 & -28 & 2.77 & 40 \\
\hline Medial frontal cortex & -12 & 12 & -12 & 3.48 & 203 \\
\hline
\end{tabular}

ApoE: Apolipoprotein E;

$x, y$, and $z$ values localise the areas of hypoperfusion according to the MNI stereotactic coordinates. R: right, L: left

No definite genetic risk factor of non-monogenic FTLD has been identified yet. Although the role of the $\varepsilon 4$ allele of ApoE has been well established in AD, studies of ApoE allele distribution in patients with FTLD have produced variable results. Literature data on the role of ApoE genotype as a risk factor for FTLD development are controversial. Some studies have reported an increased frequency of the ApoE $\varepsilon 4$ allele in FTLD; others have found no relationship between ApoE genotype and the risk of FTLD development [26-31]. Our results suggest higher ApoE $\varepsilon 4$ allele frequency in FTLD (39.1\%) compared to the reported incidence in healthy control subjects.

Notwithstanding, data on a possible modulating effect of ApoE genotype on functional and neuropsychological features have not been available yet. The data of the present work, if replicated in larger studies with neuropathological confirmation, may have implications for our understanding of the pathogenesis of FTLD and factors influencing the regional predilection. The fact that the ApoE $\varepsilon 4$ genotype in our patients was associated with greater hippocampus hypoperfusion suggests the existence of common ApoE-related pathways involved in the development of different clinical FTLD subtypes.

\section{Conclusion}

Our study carried out in a group of patients from the same geographical area and well characterized from the neuropsychological, neurological and imaging point of view suggests that ApoE genotype might be considered a disease-modifying factor in FTLD, thus contributing to define a specific clinical presentation.

\section{Abbreviations}

FTLD: Frontotemporal Lobar Degeneration; ApoE: Apolipoprotein E; SPECT: Single Photon Emission Tomography; fvFTD: frontal variant of frontotemporal dementia; SD: Semantic Dementia; PNFA: Progressive Non-fluent Aphasia; PSP: Progressive Supranuclear Palsy; CBD: Corticobasal Degeneration; CSF: cerebrospinal fluid.

\section{Competing interests}

The author(s) declare that they have no competing interests.

\section{Authors' contributions}

$\mathrm{BB}$ conceived of the study, and participated in its design and coordination and in the draft of the manuscript; DP participated in the design of the study, in neuroimaging analyses and revised the manuscript critically for intellectual content; BP has made substantial contributions in the acquisition of the data and performed the statistical analysis; CA and GB performed the clinical evaluation of the patients and have made substantial contribution to interpretation of data; SA and MDL performed the genetic analysis and have been involved in revising it critically for important intellectual content; AP conceived of the study, and participated in its design and in coordination and drafted the manuscript. All authors read and approved the final manuscript.

\section{Acknowledgements}

The authors wish to thank the patients and their families for their kind participation in this study. The authors are in debt with Michela Cossandi for valuable technical support, and to $\mathrm{Dr}$ Antonella Alberici for critical review of the manuscript.

\section{References}

I. Kertesz A, Munoz DG: Pick's disease and Pick complex. WileyLiss, New York; 1998.

2. Graham A, Davies R, Xuereb J, Halliday G, Kril J, Creasey H, Graham $\mathrm{K}$, Hodges J: Pathologically proven frontotemporal dementia presenting with severe amnesia. Brain 2005, I 28:597-605.

3. Corder EH, Saunders AM, Strittmatter WJ, Schmechel DE, Gaskell FTLD, Small GW, Roses AD, Haines JL, Pericak-Vance MA: Gene dose of apolipoprotein $E$ type 4 allele and the risk of Alzheimer's disease in late onset families. Science 1993, 261:921-923.

4. Schott J, Ridha BH, Crutch SJ, Healy DG, Uphill JB, Warrington EK, Rossor MN, Fox NC: Apolipoprotein E genotype modifies the phenotype of Alzheimer disease. Arch Neurol 2006, 63:I57-I58.

5. Lantos PL: Diagnostic criteria for corticobasal degeneration. J Neurol Neurosurg Psychiatry 2000, 69:705-706.

6. Litvan I, Agid Y, Calne D, Campbell G, Campbell G, Dubois B, Duvoisin RC, Goetz CG, Golbe LI, Grafman J, Growdon JH, Hallett M, Jankovic J, Quinn NP, Tolosa E, Zee DS: Clinical research criteria for the diagnosis of progressive supranuclear palsy (Steele-Richardson-Olszewski syndrome): report of the NINDS-SPSP international workshop. Neurology 1996, 47: I-9.

7. Neary D, Snowden JS, Gustafson L, Passant U, Stuss D, Black S, Freedman M, Kertesz A, Robert PH, Albert M, Boone K, Miller BL, Cummings J, Benson DF: Frontotemporal lobar degeneration: a 
consensus on clinical diagnostic criteria. Neurology 1998, 5 I: I546-I554.

8. Folstein MF, Folstein SE, McHugh PR: "Mini-Mental State": a practical method for grading the cognitive state of patients for the clinician. J Psychiatr Res 1975, I 2:189-98.

9. Bingham WC, Burke HR, Murray S: Raven's Progressive Matrices: construct validity. I Psycgol 1966, 62:205-9.

10. Isaacs B, Kennie AT: The Set test as an aid to the detection of dementia in old people. Br J Psychiatry 1973, 123:467-470.

II. Wolf-Klein GP, Silverstone FA, Levy AP, Brod MS: Screening for Alzheimer's disease by clock drawing. J Am Geriatr Soc 1989, 37:730-4.

12. Loring DW, Martin RC, Meador KJ: Psychometric construnction of the Rey-Osterrieth Complex Figure. Arch Clin Neuropsych 1990, 5:1-14

13. Babcock $H$, Levy L: The measurement of mental efficiency of mental functioning (revised examination). In Test and manual of directions Chicago: $\mathrm{CH}$ Stoelting; 1940.

14. Blackburn HL, Benton AL: Revised administration and scoring of the digit span test. J Consult Psychol 1957, 2 1:139-43.

15. Reitan RM: Validity of the Trail Making Test as an indicator of organic brain damage. Perceptual and motor skills 1958, 8:27|-76.

16. De Renzi E, Vignolo LA. The Token Test: a sensitive test to detect receptive disturbances in aphasics. Brain 1962, 85:665-78.

17. De Renzi E, Motti F, Nichelli P: Imitating gestures. A quantitative approach to ideomotor apraxia. Arch Neurol 1980, 37:6-10.

18. Lawton MP, Broody EM: Assessment of older people: self-maintaining and instrumental activities of daily living. The Gerontologist 1969, 9:179-186.

19. Sheikh K, Smith DS, Meade TW, Goldenberg E, Brennan PJ, Kinsella G: Repeatibility and validity of a modified Activities of Daily Living (ADL) Index in studies of chronic disability. Int Rehabil Med 1979, 1:51-58.

20. Cummings JL, Mega M, Gray K, Rosenberg-Thompson S, Carusi DA, Gornbein J: The Neuropsychiatric Inventory: comprehensive assessment of psychopathology in dementia. Neurology 1994, 44:2308-14.

21. Kertesz A, Nadkarni N, Davidson W, Thomas AW: The Frontal Behavioral Inventory in the differential diagnosis of frontotemporal dementia. J Int Neuropsychol Soc 2000, 6:460-8.

22. Tatsch K, Asenbaum S, Bartenstein P, Catafau A, Halldin C, Pilowsky LS, Pupi A, European Association of Nuclear Medicine: European Association of Nuclear Medicine. European Association of Nuclear Medicine procedure guidelines for brain perfusion SPET using $(99 \mathrm{~m})$ Tc-labelled radiopharmaceuticals. Eur J Nucl Mol Imaging 2002, 29:BP36-42.

23. Friston $\mathrm{KJ}$ : Testing for anatomically specified regional effects. Hum Brain Mapp 1997, 5:133-6.

24. Mosconi L, Perani D, Sorbi S, Herholz K, Nacmias B, Holthoff $V$, Salmon E, Baron JC, De Cristofaro MT, Padovani A, Borroni B, Franceschi M, Bracco L, Pupi A: MCl conversion to dementia and the APOE genotype: a prediction study with FDG-PET. Neurology 2004, 63:2332-2340.

25. Reiman EM, Caselli RJ, Yun LS, Chen K, Bandy D, Minoshima S, Thibodeau SN, Osborne D: Preclinical evidence of Alzheimer's disease in persons homozygous for the epsilon 4 allelle of apolipoprotein E. New Eng J Med 1996, 334:752-758.

26. Borroni B, Yancopoulou D, Tsutsui M, Padovani A, Sawcer SJ, Hodges JR, Spillantini MG: Association between tau $\mathbf{H} 2$ haplotype and age at onset in frontotemporal dementia. Arch Neurol 2005 62:1419-1422.

27. Gustafson L, Abrahamson M, Grubb A, Nilsson K, Fex G: (1997) Apolipoprotein-E genotyping in Alzheimer's disease and frontotemporal dementia. Dement Geriatr Cogn Disord 1997, 8:240-243.

28. Srinivasan R, Davidson $Y$, Gibbons L, Payton A, Richardson AM, Varma A, Julien C, Stopford C, Thompson J, Horan MA, Pendleton N, Pickering-Brown SM, Neary D, Snowden JS, Mann DM: The apolipoprotein $E$ epsilon 4 allele selectively increases the risk of frontotemporal lobar degeneration in males. I Neurol Neurosurg Psychiatry 2006, 77:154-8.

29. Short RA, Graff-Radford NR, Adamson J, Baker M, Hutton M: Differences in tau and apolipoprotein $E$ polymorphism frequencies in sporadic frontotemporal lobar degeneration syndromes. Arch Neurol 2002, 59:6। I-5.
30. Fabre SF, Forsell C, Viitanen M, Sjogren M, Wallin A, Blennow K, Blomberg M, Andersen C, Wahlund LO, Lannfelt L: Clinic-based cases with frontotemporal dementia show increased cerebrospinal fluid tau and high apolipoprotein E epsilon4 frequency, but no tau gene mutations. Exp Neurol 200 I, 168:413-8.

3I. Geschwind D, Karrim J, Nelson SF, Miller B: The apolipoprotein E epsilon 4 allele is not a significant risk factor for frontotemporal dementia. Ann Neurol 1998, 44:134-8.

\section{Pre-publication history}

The pre-publication history for this paper can be accessed here:

http://www.biomedcentral.com/1471-2377/6/31/prepub
Publish with Bio Med Central and every scientist can read your work free of charge

"BioMed Central will be the most significant development for disseminating the results of biomedical research in our lifetime. "

Sir Paul Nurse, Cancer Research UK

Your research papers will be:

- available free of charge to the entire biomedical community

- peer reviewed and published immediately upon acceptance

- cited in PubMed and archived on PubMed Central

- yours - you keep the copyright
BioMedcentral 